PAPers in Physics, VOL. 12, ART. 120005 (2020)

Received: 25 April 2020, Accepted: 30 July 2020

Edited by: D. Peres Menezes

Reviewed by: E. M. Yoshimura, Instituto de Física da Univ. de São Paulo, Brazil

Licence: Creative Commons Attribution 4.0

DOI: https://doi.org/10.4279/PIP.120005

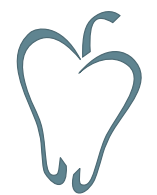

ISSN 1852-4249

\title{
Optimizing the shielding properties of strength-enhanced concrete containing marble
}

\begin{abstract}
A. Abdel-Latif M. ${ }^{1,2 *}$, M. I. Sayyed ${ }^{3}$, H. O. Tekin ${ }^{4,5}$, M. M. Kassab ${ }^{1}$
The purpose of this study is to develop a low cost, locally produced concrete mixture with optimum marble content. The resulting mixture would have enhanced strength properties compared to the non-marble reference concrete, and improved radiation shielding properties. To accomplish these goals five concrete mixtures were prepared, containing $0,5,10$, 15 and $20 \%$ marble waste powder as a cement replacement on the basis of weight. These samples were subjected to a compressive strength test. The shielding parameters such as mass attenuation coefficients $\left(\mu_{m}\right)$, mean free path (MFP), effective atomic number $\left(Z_{e f f}\right)$ and exposure build-up factors (EBF) were measured, and results were compared with those obtained using the WinXcom program and MCNPX code in the photon energy range of 0.015 - $3 \mathrm{MeV}$. Moreover, the macroscopic fast neutron removal cross-section (neutron attenuation coefficient) was calculated and the results presented. The results show that the sample containing $10 \%$ marble has the highest compressive strength and potentially good gamma ray and neutron radiation shielding properties.
\end{abstract}

\section{Introduction}

Radiation shielding has recently become an important research topic in nuclear science, and is defined as the ability to reduce radiation effects through interaction with the shielding material. Several parameters such as attenuation effectiveness, strength, and thermal properties influence the

* aam00@fayoum.edu.eg

1 Department of Mathematics and Eng. Physics - Faculty of Engineering - Fayoum University, 63514 Fayoum, Egypt.

2 College of Industry and Energy Technology - New Cairo Technological University, Cairo, Egypt.

3 Department of Physics, Faculty of Science - University of Tabuk, Saudi Arabia.

4 Department of Radiotherapy, Vocational School of Health Services, Uskudar University, Turkey.

5 Medical Radiation Research Center (USMERA), Uskudar University, Turkey. selection of radiation shielding materials. Concrete is one of the most widely used materials in reactor shielding due to its intrinsic properties, such as cheapness, and the ease of preparation of different compositions and forms. Moreover, its shielding properties depend strongly on the elemental composition of the prepared mixtures. An enormous amount of solid waste is generated annually in Egypt as a by-product of mining, agricultural and industrial processes. Due to various economic, social, and environmental restraints, the development of a suitable waste disposal method remains a top priority. The non-degradable waste by-products of mining and industry have long been targeted in research on concrete production. Several researchers investigated the possible use of industrial by-products such as steel shots [1], steel particulates, used steel ball-bearings [2], electric arc furnace slag [3] and stone slurry [4], either as fine or coarse aggregates in concrete, and their effects on mechanical and radiation shielding properties 
were evaluated. Among these mining and industrial by-products is marble dust powder, generated during the marble cutting process. Marble processing plants cannot store large amounts of marble dust powder, so reusing it is of great environmental and economic benefit [5] and [6]. Corinaldesi et al. (2010) found that replacing sand with marble powder at a rate of $10 \%$ provides maximum compressive strength [7]. Akkurt and Altindag (2012) determined, both experimentally and theoretically, the linear attenuation coefficients of concrete containing marble powder in its fine aggregate form. The measured and calculated linear attenuation coefficients showed good agreement. Finally, they concluded that marble can be used as an aggregate in the production of shielding concrete [8]. Akkurt and EL-Khayatt (2013) also calculated the photon interaction parameters for concrete containing marble dust for the photon energy range of $1 \mathrm{keV}-100$ $\mathrm{GeV}$ [10]. Aliabdo et al. (2014) found that using marble powder as a partial replacement for cement or sand improves the physical properties of concrete [9]. Ergün (2015) utilized marble powder together with diatomite as a partial replacement for cement. He found that either $5 \%$ marble powder alone or $5 \%$ marble powder along with $10 \%$ diatomite can be used to enhance the mechanical properties of concrete [11]. Furthermore, it was found that up to $10 \%$ marble powder enhances the workability of the mixture, while maintaining its compressive strength [12]. In a recent review it was found that as the amount of marble powder fine aggregate increases within the mixture, concrete workability decreases, and the compressive strength of the concrete increases because of its $\mathrm{CaCO}_{3}$ and $\mathrm{SiO}_{2}$ content [13]. Moreover, the cement with optimal concrete strength was obtained using $10 \%$ waste marble as a replacement for cement [14] and [15]. The purpose of this study is to develop a low cost, locally produced concrete mixture with optimum marble content, which is stronger than ordinary concrete and has enhanced gamma-ray and neutron shielding properties.

\section{Theoretical basis and calculations}

\section{i. The mass attenuation coefficient, $\mu_{m}$}

A mono-energetic gamma ray passing through matter is attenuated due to photoelectric absorption, scattering, and pair-production. Attenuation behavior follows Beer-Lambert's law [8, 9,16]

$$
I=I_{0} e^{-\mu_{i} d},
$$

where the incident and the transmitted photon intensities are denoted by $I_{0}$ and $I$ respectively. Moreover, $d$ and $\mu_{i}$ are the thickness and the linear attenuation coefficient, respectively. Also, the mass attenuation coefficient $\mu_{m}$ can be calculated by:

$$
\mu_{m}=\sum_{i} \omega_{i} \frac{\mu_{i}}{\rho_{i}}
$$

where $\omega_{i}, \mu_{i}$ and $\rho_{i}$ are the weight fraction, linear attenuation coefficient, and the density of the $i^{\text {th }}$ constituent element. The mean free path $(M F P)$ is the average distance traveled by a moving particle between successive impacts (collisions)

$$
M F P=\frac{1}{\mu},
$$

where $\mu$ is the linear attenuation coefficient.

\section{ii. Effective atomic number, $\mathbf{Z}_{\text {eff }}$}

The effective atomic number for low- $Z$ elements due to the inelastic scattering of gamma rays with material atoms is given by Eq. 4 below [16-19], while for high- $Z$ elements such as molybdenum through uranium, the uncertainties at low energies (10 keV to $1 \mathrm{MeV}$ ) range from 1 to 2 percent far from an absorption edge to 5 to 10 percent in the vicinity of an edge. In the range 1 to $100 \mathrm{MeV}$ uncertainties from pair production estimates are 2 to 3 percent, while above $100 \mathrm{MeV}$ they are 1 to 2 percent [20].

$$
Z_{\text {eff }}=N_{A} \frac{\sum_{i} f_{i} A_{i} \frac{\mu_{i}}{\rho_{i}}}{\sum_{i} f_{i} \frac{A_{i}}{Z_{i}} \frac{\mu_{i}}{\rho_{i}}},
$$

where $N_{\mathrm{A}}$ is Avogadro's number, $\mu_{i}$ is the linear attenuation coefficient, $\rho_{i}$ is the density, $A_{i}$ is the atomic mass, $Z_{i}$ is the atomic number and $f_{i}$ is the mole fraction of the $i^{\text {th }}$ constituent element. Mole fraction $f_{i}$ is given by

$$
f_{i}=\frac{\left(\omega_{i} / A_{i}\right)}{\sum_{i}\left(\frac{\omega}{A}\right)_{i}},
$$

where omega $a_{i}$ is the weight fraction. 


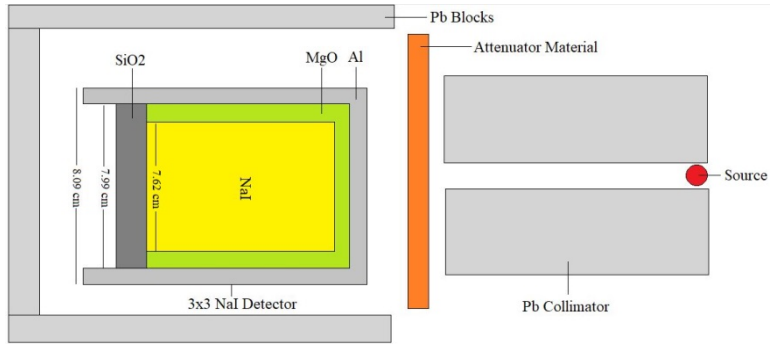

Figure 1: Schematic diagram of the modeled $\mathrm{NaI}(\mathrm{Tl})$ detector with simulation geometry.

\section{iii. MCNPX code (version 2.6.0)}

The Monte Carlo method is often employed for issues with a probabilistic structure. In this study, MCNPX (Monte Carlo N-Particle Transport Code System-extended) version 2.6.0 [21] was used to investigate the $\mu_{m}$ of different concrete mixtures $[22,23]$. The schematic diagram shows the MCNPX gamma ray attenuation setup with five main pieces of simulation equipment: point isotropic radiation source, $\mathrm{Pb}$ collimator for primary radiation beam, attenuator concrete sample, $\mathrm{Pb}$ blocks to prevent scattered radiation and $\mathrm{NaI}(\mathrm{Tl})$ detector (see Fig. 1) $[22,23]$. The relative error rate observed was less than $0.1 \%$ in the output file.

\section{iv. Exposure build-up factor, EBF}

During the penetration of gamma photons through any material, they may be either absorbed or scattered by the atoms of this material. Secondary radiation may arise due to the build-up of scattered photons inside the material. Accordingly, it is necessary to estimate these build-up factors to determine effective exposure and energy deposition in the shielding material. The build-up of secondary radiation is characterized by the exposure buildup factor $(\mathrm{EBF})$, defined as the ratio of the total gamma photon flux (absorbed and scattered) to the absorbed gamma photons of the incident beam $[24,25]$. In this work, the geometrical progression (G-P) fitting method [26] was used due to a high level of accuracy. The ratio $R=\mu_{\text {comp }} / \mu_{m}$, which represents the relative contribution of the mass attenuation coefficient due to Compton scattering interaction $\left(\mu_{c o m p}\right)$, was obtained for each sample over the photon energy range of $0.015-3 \mathrm{MeV}$. The ratio $R$ at a given energy value was then matched with the corresponding ratios $R_{1}$ and $R_{2}$ of known elements whose atomic numbers were $Z_{1}$ and $Z_{2}$, respectively, where $R_{1}<R<R_{2}$. The equivalent atomic number $\left(Z_{e q}\right)$ for each sample was obtained using the following formula of interpolation by [24-26]:

$$
Z_{\text {eq }}=\frac{Z_{1} \log \left(R_{2} / R\right)+Z_{2} \log \left(R / R_{1}\right)}{\log \left(R_{2} / R_{1}\right)} .
$$

The build-up factors for each sample were calculated using the geometrical progression fitting function $B(E, x)$ and $K(E, x)$.

$$
\begin{gathered}
B(E, x)=\left\{\begin{array}{ll}
1+(b-1) \frac{\left(K^{x}-1\right)}{(K-1)} & K \neq 1 \\
1+(b-1) x & K=1
\end{array}, \quad(7)\right. \\
K(E, x)=c x^{a}+d \frac{\tanh \left(\frac{x}{X_{K}}-2\right)-\tanh (-2)}{1-\tanh (-2)},
\end{gathered}
$$

where Eq. (8) is valid for $x \leq 40 M F P$ and $\mathrm{x}$ is the source-to-detector distance in terms of the MFP. The geometrical progression parameters (b, c, a, $X_{K}$ and $d$ ) for the selected samples were obtained in advance using the following interpolating formula:

$$
P=\frac{P_{1} \log \left(Z_{2} / Z_{\mathrm{eq}}\right)+P_{2} \log \left(Z_{\mathrm{eq}} / Z_{1}\right)}{\log \left(Z_{2} / Z_{1}\right)},
$$

where $P$ stands for the required G-P fitting parameter for the selected sample at a specific energy value, while $P_{1}$ and $P_{2}$ represent the values of the G-P fitting parameter corresponding to the atomic numbers $Z_{1}$ and $Z_{2}$, respectively. The G-P fitting parameters $P_{1}$ and $P_{2}$ can be obtained from the American National Standard database which contains the exposure buildup G-P fitting parameters for 23 different elements, one compound (water), and one mixture (concrete) for different energies [24-26].

\section{v. The macroscopic effective removal cross- section for fast neutron $\Sigma_{R}$}

The attenuation of neutrons in matter obeys the following law:

$$
I=I_{0} \exp \left(-\Sigma_{R} x\right)
$$


The effective fast neutron removal cross-section (neutron attenuation coefficient), $\Sigma_{R}$, for a compound or a homogeneous mixture may be calculated using the values $\Sigma_{R} / \rho$ for various elements in the compound or mixture, using the following equations [27-34]

$$
\begin{gathered}
\Sigma_{R} / \rho=\sum_{i} W_{i}\left(\Sigma_{R} / \rho\right)_{i} \\
\rho=\sum_{i} \rho_{i}\left(\Sigma_{R} / \rho\right)_{i} .
\end{gathered}
$$

Where $W_{i}$ is the weight percentage, and $\rho_{i}$ and $\left(\Sigma_{R} / \rho\right)_{i}$ are the partial density and the mass fast neutron removal cross-section (mass attenuation coefficient) of the $i^{\text {th }}$ constituent, respectively.

\section{Materials and experimental pro- cedures}

\section{i. Materials}

The fine aggregate used is natural siliceous yellow sand with a particle size less than $0.6 \mathrm{~mm}$, with Ordinary Portland Cement (OPC) produced by the Beni-Suef cement factory, in Egypt. Also, the marble powder is white-colored and odorless, with quite low porosity and a grain-size less than $0.365 \mathrm{~mm}$.

\section{ii. Concrete sample preparation}

The experimental part of this study has three main goals: to analyze changes in the concrete chemical composition, to monitor the compressive strength, and evaluate the enhancement of the gamma shielding properties due to the incorporation of marble dust as a partial replacement for cement, on a weight basis. In order to achieve these goals, five different concrete mixtures were prepared where marble was used at a rate of $0 \%, 5 \%, 10 \%$, $15 \%$ and $20 \%$, and tagged as $\mathrm{CM}_{1}, \mathrm{CM}_{2}, \mathrm{CM}_{3}$, $\mathrm{CM}_{4}$ and $\mathrm{CM}_{5}$, respectively. The variation in the samples was carried out in such a way that when the marble proportion was increased, the cement proportion was decreased by the same proportion. Accordingly, the water to cement ratio (w/c) was varied with the varying marble content in the prepared mixtures. For each mixture nine cubic samples $(5 \mathrm{~cm} \times 5 \mathrm{~cm} \times 5 \mathrm{~cm})$ were cast. Samples

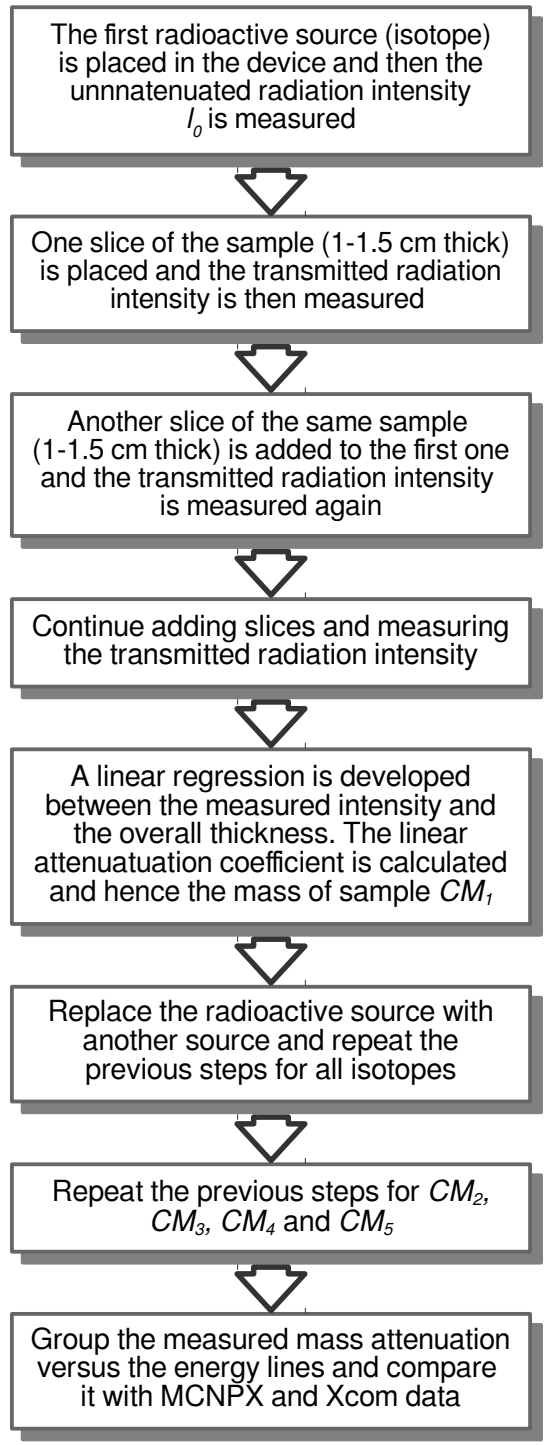

Figure 2: A flowchart describing the steps followed in the experiment to measure the mass attenuation coefficients.

used for measuring the linear attenuation coefficient were then obtained by cutting the cubic samples into slices with thicknesses varying from 1 to $1.5 \mathrm{~cm}$, and the flowchart was followed, as shown, (see Fig. 2) to calculate the mass attenuation coefficients.

The chemical composition of the constituent materials of each sample were analyzed using the Xray Fluorescence (XRF) technique; these compositions are listed in Table 1. 


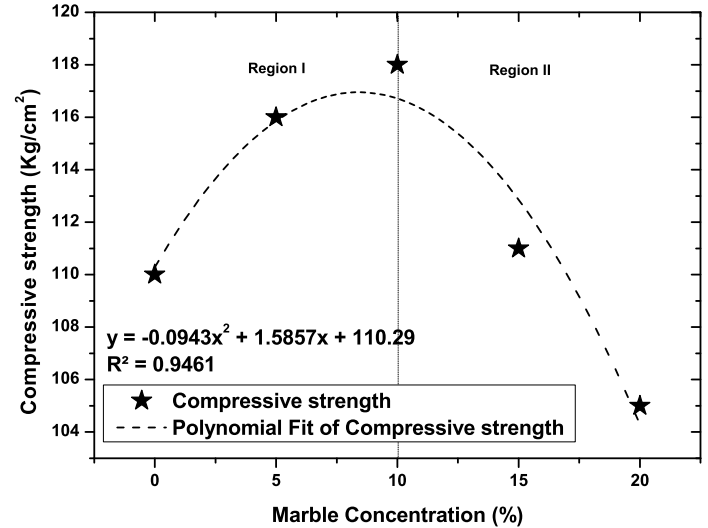

Figure 3: Compressive strength and marble concentration.

\section{iii. Compressive strength test}

For each mixture, three concrete samples were put to a compressive strength test using an ADR 2000 Standard Compression Machine $(2000 \mathrm{kN} / 450000$ lbf capacity, rated power of $1350 \mathrm{~W})$. The load was applied gradually at the rate of $140 \mathrm{~kg} / \mathrm{cm}^{2}$ per minute until the specimen failed, and the average reading was registered.

\section{iv. Gamma ray shielding parameters ex- periment}

The radiation shielding experiments were carried out with the samples placed between sources ${ }^{133}$ $\mathrm{Ba}(0.356 \mathrm{MeV}),{ }^{137} \mathrm{Cs}(0.662$ and $0.911 \mathrm{MeV})$, ${ }^{60} \mathrm{Co}(1.173$ and $1.332 \mathrm{MeV})$, and ${ }^{232} \mathrm{Th}(0.583$ and $2.614 \mathrm{MeV}$ ); a NaI(TI) detector was connected to a Multi-Channel Analyzer (MCA) with PC to mea-

Table 1: XRF analysis of the prepared mixtures.

\begin{tabular}{cccccc}
\hline \hline \multirow{5}{*}{ Chemical Composition (\% by weight) } \\
& $\mathrm{CM}_{1}$ & $\mathrm{CM}_{2}$ & $\mathrm{CM}_{3}$ & $\mathrm{CM}_{4}$ & $\mathrm{CM}_{5}$ \\
\hline $\mathrm{TiO}_{2}$ & 0.27 & 0.33 & 0.37 & 0.33 & 0.24 \\
$\mathrm{Al}_{2} \mathrm{O}_{3}$ & 2.88 & 3.27 & 3.38 & 2.86 & 2.53 \\
$\mathrm{Fe}_{2} \mathrm{O}_{3}$ & 1.89 & 2.06 & 2.38 & 1.92 & 1.55 \\
$\mathrm{MnO}$ & 0.04 & 0.05 & 0.05 & 0.04 & 0.03 \\
$\mathrm{MgO}$ & - & 0.14 & 0.64 & 0.11 & 0.03 \\
$\mathrm{CaO}$ & 19.26 & 18.69 & 20.28 & 16.95 & 15.09 \\
$\mathrm{Na}_{2} \mathrm{O}$ & 0.14 & 0.24 & 0.11 & 0.08 & 0.15 \\
$\mathrm{SiO}_{2}$ & Balance & Balance & Balance & Balance & Balance \\
\hline \hline
\end{tabular}

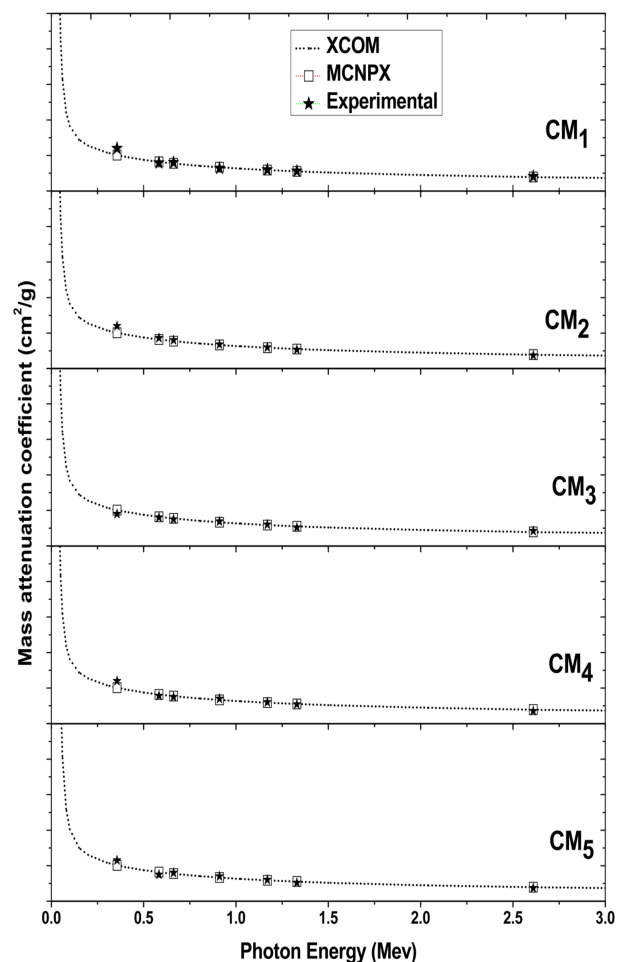

Figure 4: The measured mass attenuation coefficient compared with that determined by MCNPX and WinXCom.

sure the linear gamma ray attenuation coefficient of each sample struck by gamma radiation.

\section{Results and discussion}

\section{i. Compressive strength}

The relationship between marble powder content and compressive strength is shown in Fig. 3. It can be seen that the compressive strength of concrete containing marble increases as the marble content increases, until it reaches an absolute maximum value at a marble cement-replacement ratio of $10 \%$ (Region I), after which it starts to decrease as the marble content increases (Region II). Thus, maximum compressive strength is typically obtained with the use of $10 \%$ waste marble powder, in good agreement with the literature [13-15]. This may be attributed to the higher content of $\mathrm{Fe}_{2} \mathrm{O}_{3}$ and $\mathrm{CaO}$ in sample $\mathrm{CM}_{3}$ than in the other samples, as well as its higher density. 


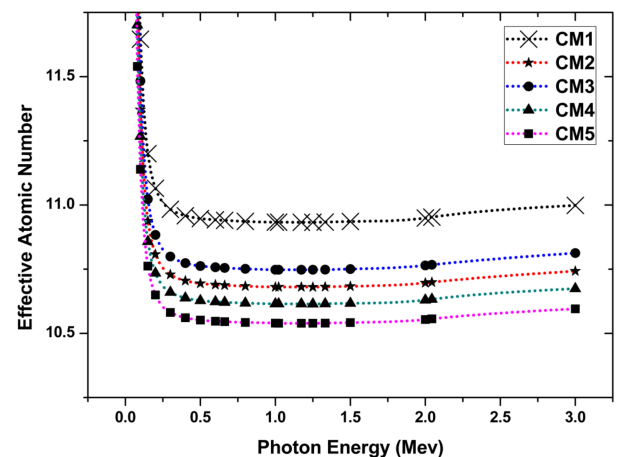

Figure 5: The effective atomic number, $Z_{\text {eff }}$, as a function of the incident photon energy.

\section{ii. Gamma ray shielding parameters}

The mass attenuation coefficient, $\mu_{m}$, was experimentally measured at different photon energy lines, and these results were then compared with those obtained theoretically using WinXCom software and the Monte-Carlo simulation code MCNPX for a photon energy range of $0.015-3 \mathrm{MeV}$. These results are displayed in Fig. 4. It can be clearly seen that there is good agreement between the theoretically calculated $\mu_{m}$ and that measured experimentally. Moreover, for very low photon energy $(E<15 \mathrm{keV})$, the mass attenuation coefficient $\mu_{m}$ has a very high value due to dominance of the photo-electric interaction. It then decreases as the incident photon energy increases, until it reaches a minimum value at a photon energy of $3 \mathrm{MeV}$. Using Eq. (4) together with the calculated mass attenuation coefficient, the effective atomic number is obtained over the photon energy range of 0.015 $3 \mathrm{MeV}$ and displayed in Fig. 5.

For very small decreases in energy down to a minimum value of $1.0 \mathrm{MeV}$, then slightly increasing again as the energy increased to $3 \mathrm{MeV}$, it was found that sample $\mathrm{CM}_{1}$ had the highest effective atomic number, followed by $\mathrm{CM}_{3}$. Moreover, it is worth noting that the addition of marble led to a decrease in the effective atomic number. The MFP values for the different marble concentrations were calculated using MCNPX simulation code at different energy lines within the range $0.015-3 \mathrm{MeV}$. The values obtained (see Fig. 6) show where the mixture $\mathrm{CM}_{3}$ has the minimum numerical value for the MFP. However, the addition of marble did not

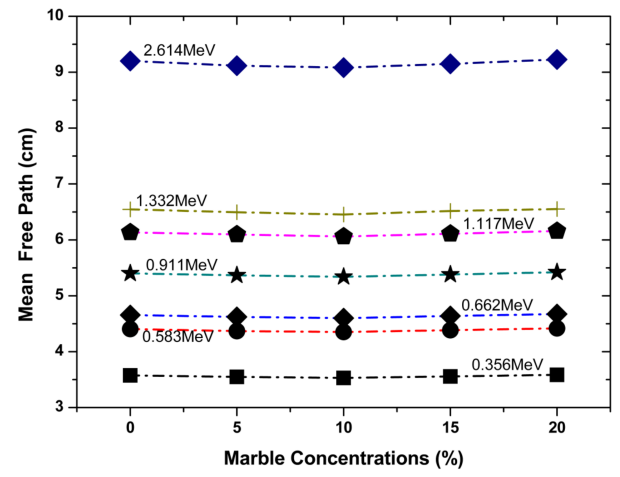

Figure 6: MFP and marble concentration at different energy lines.

lead to a significant change in the MFP.

\section{iii. The energy exposure build-up factor, EBF}

Variation in the EBF with photon energy at the penetration depths of $1,5,10$ and 40 MFP is shown in Fig. 7 (a-d). It is clear that the EBF value increases as the energy of the incident photon increases, until it reaches a maximum value, after which it decreases as the penetration depth increases. At this peak point, the Compton scattering interaction is the dominant mechanism. This is followed by a decrease in the build-up factors with
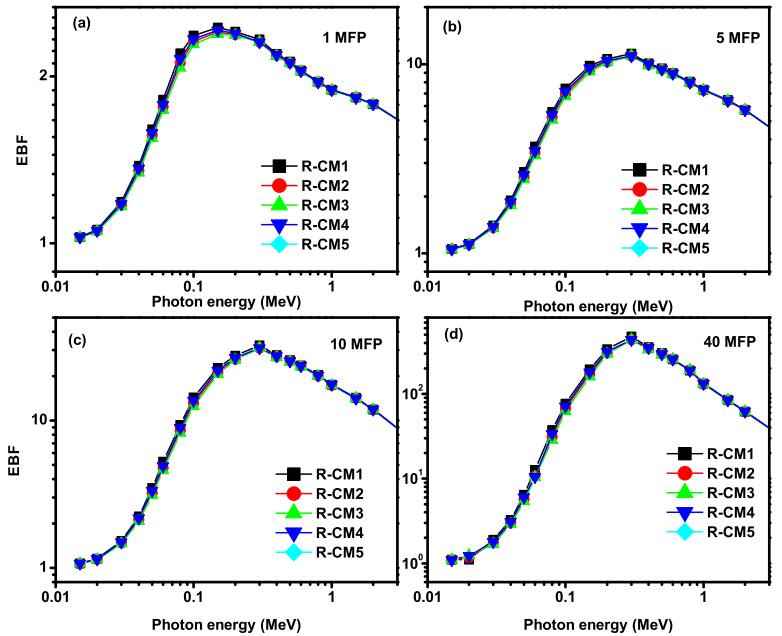

Figure 7: The EBF as a function of photon energy at 1, 5, 10 and 40 MFP depth. 

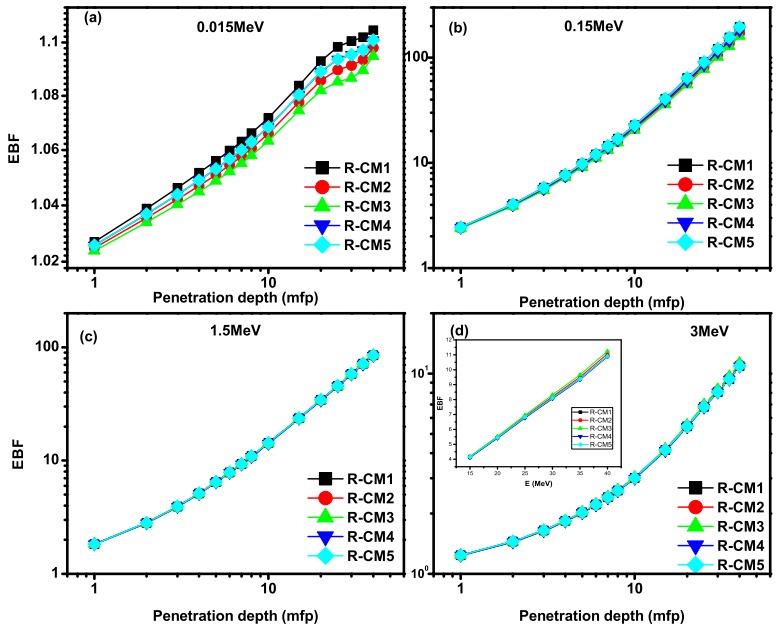

Figure 8: The EBF and penetration depth at photon energies $0.015,0.15,1.5$ and $3 \mathrm{MeV}$.

any further increase in the energy of the incident photon, due to an increase in the contribution of the pair-production interaction at the expense of the Compton scattering [33,35].

Variation in the EBF with penetration depth for the different concrete mixtures at an incident photon energy of $0.015,0.15,1.5$ and $3 \mathrm{MeV}$ is shown in Fig. 8 (a-d). It can be seen that the EBF increases with increased penetration depth for all concrete mixtures. At a photon energy of $0.015 \mathrm{MeV}$, where photoelectric absorption is the dominant mechanism, the EBF shows that $\mathrm{CM}_{3}$ has better gamma ray shielding properties than the other samples. In contrast, at the higher energies of $0.15,1.5$ and 3 $\mathrm{MeV}$ the EBF is independent of marble concentration.

\section{iv. The effective removal cross section for fast neutrons (neutron attenuation co- efficient)}

The calculations of the fast neutron removal crosssection for the prepared samples are listed in Table 2. Variation in the neutron mean free path with marble powder concentration is illustrated in Fig. 9. The results show that sample $\mathrm{CM}_{3}$ has, numerically, the minimum value for the neutron mean free path. Similar to the case of gamma ray MFP, the addition of marble did not lead to a significant change in the fast neutron MFP.

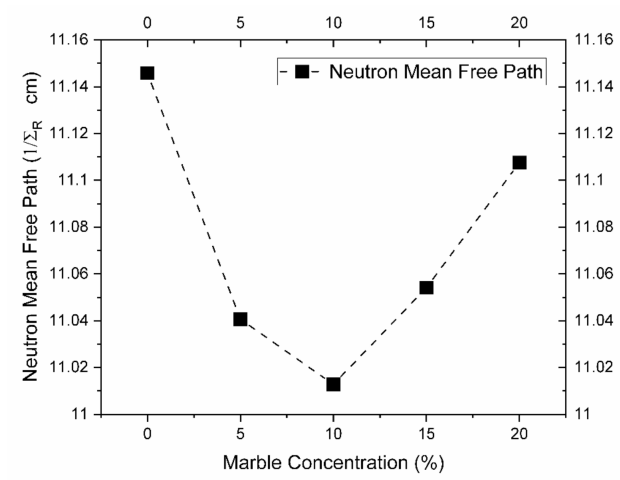

Figure 9: The Neutron MFP and marble concentrations.

\section{Conclusions}

The following conclusions can be drawn:

- The replacement of cement by marble waste powder enhances compressive strength, as replacing $10 \%$ of cement with marble powder $\left(C M_{3}\right)$ led to an increase of $10 \%$ in compressive strength with respect to the measured value for reference sample $\mathrm{CM}_{1}$. This may be attributed to the higher content of $\mathrm{Fe}_{2} \mathrm{O}_{3}$ and $\mathrm{CaO}$ than in the other samples, and is economically beneficial.

- Based on the mass attenuation coefficients, the effective atomic number, $Z_{\text {eff }}$, and the mean free path were calculated for the different mixtures. It was found that sample $\mathrm{CM}_{3}$, which contained $10 \%$ marble, had better gamma and neutron shielding properties (i.e., minimum MFP and maximum effective atomic number $Z_{\text {eff }}$ than the other mixtures. This may be due to its higher density compared to the other mixtures.

- At the photon energy of $0.015 \mathrm{MeV}$, where photoelectric absorption is the dominant mechanism, the EBF shows that $\mathrm{CM}_{3}$ has better gamma ray shielding properties than the other samples, while for $\mathrm{E}>0.015 \mathrm{MeV}$ it is composition-independent. 
Papers in Physics, vol. 12, ART. 120005 (2020) / A. Abdel-Latif M. et al.

Table 2: Calculations of the fast neutron removal cross-section for the prepared samples.

\begin{tabular}{ccccccccccc}
\hline \hline Element & \multicolumn{2}{c}{$\mathrm{CM}_{1}$} & \multicolumn{2}{c}{$\mathrm{CM}_{2}$} & \multicolumn{2}{c}{$\mathrm{CM}_{3}$} & \multicolumn{2}{c}{$\mathrm{CM}_{4}$} & \multicolumn{2}{c}{$\mathrm{CM}_{5}$} \\
& Part. dens. & $\Sigma_{R} \mathrm{~cm}^{-1}$ & Part. dens. & $\Sigma_{R} c m^{-1}$ & Part. dens. & $\Sigma_{R} c m^{-1}$ & Part. dens. & $\Sigma_{R} \mathrm{~cm}^{-1}$ & Part. dens. \\
\hline $\mathrm{Al}$ & 0.0422 & 0.0012 & 0.0483 & 0.0014 & 0.0502 & 0.0015 & 0.0421 & 0.0012 & 0.0370 & 0.0011 \\
$\mathrm{Fe}$ & 0.0366 & 0.0008 & 0.0402 & 0.0009 & 0.0467 & 0.0010 & 0.0374 & 0.0008 & 0.0299 & 0.0006 \\
$\mathrm{Ca}$ & 0.3812 & 0.0093 & 0.3731 & 0.0091 & 0.4066 & 0.0099 & 0.3371 & 0.0082 & 0.2978 & 0.0072 \\
$\mathrm{Si}$ & 0.9775 & 0.0246 & 0.9820 & 0.0247 & 0.9544 & 0.0241 & 1.0109 & 0.0255 & 1.0374 & 0.0261 \\
$\mathrm{O}$ & 1.3228 & 0.0536 & 1.3368 & 0.0541 & 1.3370 & 0.0541 & 1.3471 & 0.0546 & 1.3507 & 0.0547 \\
Minor & 0.0087 & 0.0002 & 0.0125 & 0.0003 & 0.0102 & 0.0003 & 0.0083 & 0.0002 & 0.0082 & 0.0002 \\
Total & 2.7690 & 0.0897 & 2.7930 & 0.0906 & 2.8050 & 0.0908 & 2.7830 & 0.0905 & 2.7610 & 0.0900 \\
\hline \hline
\end{tabular}

[1] O Gencel, A Bozkurt, E Kam, T Korkut, Determination and calculation of gamma and neutron shielding characteristics of concretes containing different hematite proportions, Ann. Nucl. Energy 38, 1274 (2011).

[2] A B Azeez, K S Mohammed, M M Bakri, A Hussin, A V Sandu, A R Razak, The effect of various waste materials' contents on the attenuation level of anti-radiation shielding concrete, Materials 2013, 6, 4836 (2013).

[3] M Maslehuddin, A Naqvi, M Ibrahim, Z Kalakada, Radiation shielding properties of concrete with electric arc furnace slag aggregates and steel shots, Ann. Nucl. Energy 53, 192 (2013).

[4] N Almeida, F Branco, J R Santos, Recycling of stone slurry in industrial activities: Application to concrete mixtures, Buil. Environ. 42 , 810 (2007).

[5] K E Alyamaç, A A Aydin, Concrete properties containing fine aggregate marble powder, K.S.C.E. J. Civ. Eng. 19, 2208 (2015).

[6] M R Kumar, S K Kumar, Partial replacement of cement with marble dust powder, Int. J. Eng. Res. Appl. 5, 106 (2015).

[7] V Corinaldesi, G Moriconi, A T Naik, Characterization of marble powder for its use in mortar and concrete, Constr. Build. Mater. 24, 113 (2010).

[8] I Akkurt, R Altindag, K Gunoglu, H Sarıkaya, Photon attenuation coefficients of concrete including marble aggregate, Ann. Nucl. Energy 43, 56 (2012).
[9] I Akkurt, A M El-Khayatt, Effective atomic number and electron density of marble concrete, J. Radioanal. Nucl. Chem. 295, 633 (2013).

[10] A A Aliabdo, M Abd Elmoaty, E M Auda, Reuse of waste marble dust in the production of cement and concrete, Constr. Build. Mater. 50, 28 (2014).

[11] A Ergun, Effects of the usage of diatomite and waste marble powder as partial replacement of cement on the mechanical properties of concrete, Constr. Build. Mater. 25, 806 (2011).

[12] K Vardhan, S Goyal, R Siddique, A M Singh, Mechanical Properties and microstructural analysis of cement mortar incorporating marble powder as partial replacement of cement, Constr. Build. Mater. 96, 615 (2015).

[13] H S Arel, Recyclability of waste marble in concrete production, J. Clean. Prod. 131, 179 (2016).

[14] E T Tunc, Recycling of marble waste: A review based on strength of concrete containing marble waste, J. Environ. Manage. 231, 86 (2019).

[15] A Khodabakhshian, J de Brito, M Ghalehnovi, E A Shamsabadi, Mechanical, environmental and economic performance of structural concrete containing silica fume and marble industry waste powder, Constr. Build. Mater. 169, 237 (2018). 
Papers in Physics, vol. 12, ART. 120005 (2020) / A. Abdel-Latif M. et al.

[16] S R Manohara, S M Hanagodimath, L Gerward, Studies on effective atomic number, electron density and kerma for some fatty acids and carbohydrates, Phys. Med. Biol. 53, N377 (2008).

[17] S R Manohara, S M Hanagodimath, L Gerward, Photon interaction and energy absorption in glass: A transparent gamma-ray shield, J. Nucl. Mater. 393, 465 (2009).

[18] V P Singh, N M Badiger, N Kucuk, Determination of effective atomic numbers using different methods for some low-Z materials, J. Nucl. Chem. 2014, (2014).

[19] V P Singh, N M Badiger, N Kucuk, Assessment of methods for estimation of effective atomic numbers of common human organ and tissue substitutes: Waxes, plastics and polymers, Radioprotection 49, 115 (2014).

[20] J H Hubbell, Photon cross-sections, attenuation coefficients, and energy absorption coefficients from 10-KeV to 100-GeV, NSRDS-NBS 29, (1969).

[21] Oak Ridge National Laboratory, MCNPX 2.4.0, Monte Carlo N-Particle transport code system for multiparticles and high energy applications., Radiation Shielding Information Center, (2004).

[22] B O El-bashir, M I Sayyed, M H M Zaid, K A Matori, Comprehensive study on physical, elastic and shielding properties of ternary $\mathrm{BaO}-\mathrm{Bi2O3-P2O5}$ glasses as a potent radiation shielding material, J. Non-Cryst. Solids 468, 92 (2017).

[23] H O Tekin, T Manici, Simulations of mass attenuation coefficients for shielding materials using the MCNP-X code, Nucl. Sci. Tech. 28, 95 (2017).

[24] Y Harima, Y Sakamoto, S Tanaka, M Kawai, Validity of the geometric-progression formula in approximating gamma-ray build-up factors, Nucl. Sci. Eng. 94, 24 (1986).

[25] J H Hubbell, S M Seltzer, X-Ray mass attenuation coefficients: NIST standard reference database 126, National Institute of Standards and Technology (1996).
[26] ANSI, Gamma-Ray attenuation coefficients $\& 6$ buildup factors for engineering materials, American National Standards Institute [ANSI] (1991).

[27] J I Wood, Computational methods in reactor shielding, Pergamon Press, New York (1982).

[28] A M El-Khayatt, A El-Sayed Abdo, MERCSF$N$ : A program for the calculation of fast neutron removal cross-section in composite shields, Ann. Nucl. Energy 36, 832 (2009).

[29] A M El-Khayatt, Calculation of fast neutron removal cross-sections for some compounds and materials, Ann. Nucl. Energy 37, 218 (2010).

[30] A M El-Khayatt, NXcom: A program for calculating attenuation coefficients of fast neutrons and gamma-rays, Ann. Nucl. Energy 38, 128 (2011).

[31] Y Elmahroug, B Tellili, C Souga, K Manai, ParShield: A computer program for calculating attenuation parameters of the gamma rays and fast neutrons, Ann. Nucl. Energy 76, 94 (2015).

[32] A El Abd, G Mesbah, M A Nader, A Ellithi, A simple method for determining the effective removal cross section for fast neutrons, J. Radiat. Nucl. Appl. 2, 53 (2016).

[33] A M Madbouly, A A El-Sawy, Calculation of gamma and neutron parameters for some concrete materials as radiation shields for nuclear facilities, Int. J. Emerging Trends in Eng. Develop. 3, 7 (2018).

[34] M M Kassab, S I El-Kameesy, M M Eissa, A Abdel-Latif M, A study of neutron and gamma-ray interaction properties with cobaltfree highly chromium maraging steel, J. Mod. Phys. 6, 1526 (2015).

[35] C Suteau, M Chiron, An iterative method for calculating gamma-ray build-up factors in multi-layer shields, Radiat. Prot. Dosim. 116, 489 (2005). 